\title{
The Mandated Adoption and Implementation of an Academic Information System: Empirical Evidence from an Indonesian University
}

\author{
Sandra Irawan \\ Universitas Negeri Malang \\ irawan.sandra@um.ac.id \\ Susan Foster \\ Monash University \\ Kerry Tanner \\ Monash University
}

\section{Abstract}

Under the scenario of contingent authority innovation-decision, organisation managers make the initial decision to adopt an innovation and mandate its use to the employees. Although accelerating adoption by the employees, the ensuing stages of implementation are often problematic partly due to its non-voluntary nature. Utilising an interpretive case study, this research aimed to explore the nature of the mandated adoption and implementation of an Academic Information System (AIS) for academics in an Indonesian University. Gallivan's (2001b) framework for innovation adoption and implementation was modified and then applied as a lens to investigate the case. The results indicated that the mediating factors (i.e., managerial interventions, subjective norms, and facilitating conditions) played a vital role in reducing the resistance resulting from the authoritarian approach to mandating usage. Based on the findings, contributions were made by extending the existing framework and providing insights for the university executives regarding the pre- and post- implementation managerial interventions.

Keywords: mandated adoption; contingent authority innovation-decision; ICT innovation; resistance; Indonesian University

\section{Introduction}

Higher education institutions worldwide have rapidly embraced ICT (Information and Communications Technology) as a solution in providing reliable and effective services to address the global increase in student enrolment (United Nations Educational, Scientific and Cultural Organization, 2009, 2014). However, ICT implementation requires higher education institutions to devise effective strategies to minimise any obstacles they may encounter (Asian Development Bank, 2011).

Rogers (2003) argued that as a social system, higher education institutions, especially those owned and operated by the government, are associated with a bureaucratic and paternalistic culture. It is imperative for information systems academics and professionals to understand the particular challenges for the implementation and adoption of an innovation that such a culture poses. Typically, an initial decision to adopt an innovation is made by the executives, who mandate the adoption to organisational members - that is, university staff and students, who have no choice but to adopt the innovation (Gallivan, 2001b; Rogers, 2003). This scenario is described as a contingent authority innovation-decision. With the contingent nature of the 
adoption, managerial interventions such as training and infrastructure support are commonly made available to ensure a successful adoption (Gallivan, 2001b; Venkatesh \& Bala, 2008). Simultaneously, subjective norms and facilitating conditions emerge as factors that mediate between the initial adoption decision by the executives and the subsequent adoption by the staff and students (Gallivan, 2001b).

In the context of higher education institutions, potential gaps exist in exploring the mandated adoption of innovations as the issue of mandatoriness was often taken for granted (Brown, Massey, Montoya-Weiss, \& Burkman, 2002; Gallivan, 2001b). In the context of higher education, research on the mandated adoption of innovations is scarce as more focus was given towards the identification of challenges and barriers for ICT usage (Al-Shboul, AlSaideh, \& Al-Labadi, 2017; Huda \& Hussin, 2010; Meerza \& Beauchamp, 2017; Setiawan, 2012) and the voluntary adoption of simple innovations (i.e. PC, laptop, internet, and office applications) (Chaputula, 2012; Othman et al., 2013; Shaikh, 2009; Wilson et al., 2014).

The significance of this research is to explore in depth the mandated adoption and implementation of an Academic Information System (AIS) for the academics in an Indonesian University. This particular university was chosen as the adoption process of the AIS by the academics was contingent upon its prior adoption by the University. The AIS was first introduced to the academics in 2012, allowing sufficient time for the assimilation to take place and for the research to assess its uptake.

This research sought to address the following questions:

1. What is the nature of the adoption and implementation of the AIS in the University?

2. How do the mediating factors influence the mandated adoption of the AIS by the academics?

By modifying Gallivan's (2001b) framework, an investigation was conducted to explore the multilevel perspectives of the actors involved in the case, including the academics, the university executives, and the administrative staff. This research contributes by refining Gallivan's (2001b) framework to suit the context of mandated innovation adoption in higher education institutions and providing insights for the university executives regarding the managerial interventions.

The paper is structured as follows. The next section presents the background of the literature related to the mandated adoption of innovations in organisations. The methodology and the results of this research are then elaborated. The paper concludes with a discussion of the findings and a conclusion.

\section{Background}

This section reviews the available literature on the adoption of innovations in organisations and higher education institutions. The preliminary conceptual framework that was used as a lens to analyse the case is presented at the end of this section.

\subsection{Organisational Adoption of Innovations}

The term 'innovation' is defined as "an idea, practice, or object that is perceived as new by an individual or other unit of adoption" (Rogers, 2003: p. 12). This definition of innovation 
implies that the degree of newness of the innovation is subjectively dependent on the perception of the individual or the organisation adopting it (Rogers, 2003; Tilton, 1971).

Rogers (2003:404) defines an organisation as "a stable system of individuals who work together to achieve common goals through a hierarchy of ranks and a division of labour". Within the context of organisations, Van De Ven and Rogers (1988) argue that innovation implementation has been recognised as a problematic issue due to failures that frequently accompany its introduction to employees.

Past studies on the broad area of innovation adoption and implementation within organisations contribute to the greater body of knowledge. Among these studies are from the area of sociology, the Diffusion of Innovation (DoI) theory (Rogers, 1962, 2003), which arose early in 1962 and evolved out of early investigations into the adoption of innovations by autonomous individuals. After more than five decades, DOI has evolved to accommodate complex organisational analyses such as when the adoption of innovations is decided at the organisational level rather than at the individual level.

In the area of information systems, among the prominent theories in innovation studies are the Technology Acceptance Model (TAM) (Davis, 1986, 1989; Davis, Bagozzi, \& Warshaw, 1989) and Information Systems (IS) Success Model (DeLone \& McLean, 1992). In particular, DeLone \& McLean's (1992) IS Success Model was then further extended by Seddon (1997). TAM was also extended to TAM2 (Venkatesh \& Davis, 2000) by taking account of social influences and facilitating conditions constructs. TAM3 (Venkatesh \& Bala, 2008) further extends the model by incorporating the determinants of perceived ease of use (Venkatesh, 2000). UTAUT (Venkatesh, Morris, G. B. Davis, \& F. D. Davis, 2003) integrates eight prominent information technology acceptance models, including DoI and TAM. In 2012, UTAUT2 (Venkatesh, Thong, \& Xu, 2012) emerged by accommodating the consumer use context.

Although considered as dominant theories for decades, the legacy of TAM and UTAUT has not been free of criticism (e.g., Bagozzi, 2007; Benbasat \& Barki, 2007; Chuttur, 2009; Lee, Kozar, \& Larsen, 2003). Among the criticisms is that TAM focused more on the decision to accept or reject an innovation made by an individual and disregarded any decision-making aspects that involved group, social, and cultural aspects (Bagozzi, 2007). Other criticisms highlight the difficulties for quantitative-based theories such as TAM and UTAUT in providing sound and actionable advice to organisational managers (Benbasat \& Barki, 2007; Brown et al., 2002; Lee et al., 2003). Moreover Benbasat and Barki (2007) believed that TAM has returned 'full circle' as the addition of new constructs in the subsequent extensions of TAM overlap with the constructs used in past theories (i.e., the Theory of Reasoned Action (Fishbein \& Ajzen, 1975) and the Theory of Planned Behaviour (Ajzen, 1985, 1991)).

Rogers (2003) criticised past studies that claimed to have investigated the determinants of innovation implementation in organisations, but only explored its initial procurement. Recent studies suggested that future research should explore the actual implementation and focus on the importance of managerial interventions (Venkatesh \& Bala, 2008). A deeper understanding of this topic can also be achieved by examining the multilevel perspectives (individual, group, and organisational levels) of the actors involved (Burton-Jones \& Gallivan, 2007; Gallivan, 2001a). Past studies investigating the multilevel perspectives of the actors and the key role of managerial interventions were limited, although they have the potential to provide managers with actionable advice regarding the various interventions that can assist implementation (Burton-Jones \& Gallivan, 2007; Venkatesh \& Bala, 2008). 
Gallivan (2001b) has provided a framework which includes an investigation of managerial interventions in the mandated adoption and implementation of an innovation. The framework is described as a hybrid as it "combines some constructs from traditional individual adoption models with features of process and stage research models of organisational-level implementation" (Gallivan, 2001b, p. 78). The hybrid nature of the framework allows for an exploration of a case from the multilevel perspectives of the actors involved.

The framework is presented in the next section.

\subsection{Gallivan's Framework for Mandated Adoption of Innovations}

As shown in Figure 1, Gallivan's (2001b) framework follows the scenario of contingent authority innovation-decisions, in which innovation adoption is regarded as a two-stage process (Leonard-Barton \& Deschamps, 1988; Zaltman, Duncan, \& Holbek, 1973), consisting of a primary adoption by organisation managers, followed by a secondary adoption by the employees (Frambach \& Schillewaert, 2002; Gallivan, 2001b). Upon developing the framework, Gallivan utilised it to investigate the implementation of a client/server development in the IS (Information Systems) division of four large insurance firms. He further advocated the use of the framework as a theoretical lens for future research to analyse the organisational adoption and implementation of innovations in different contexts.

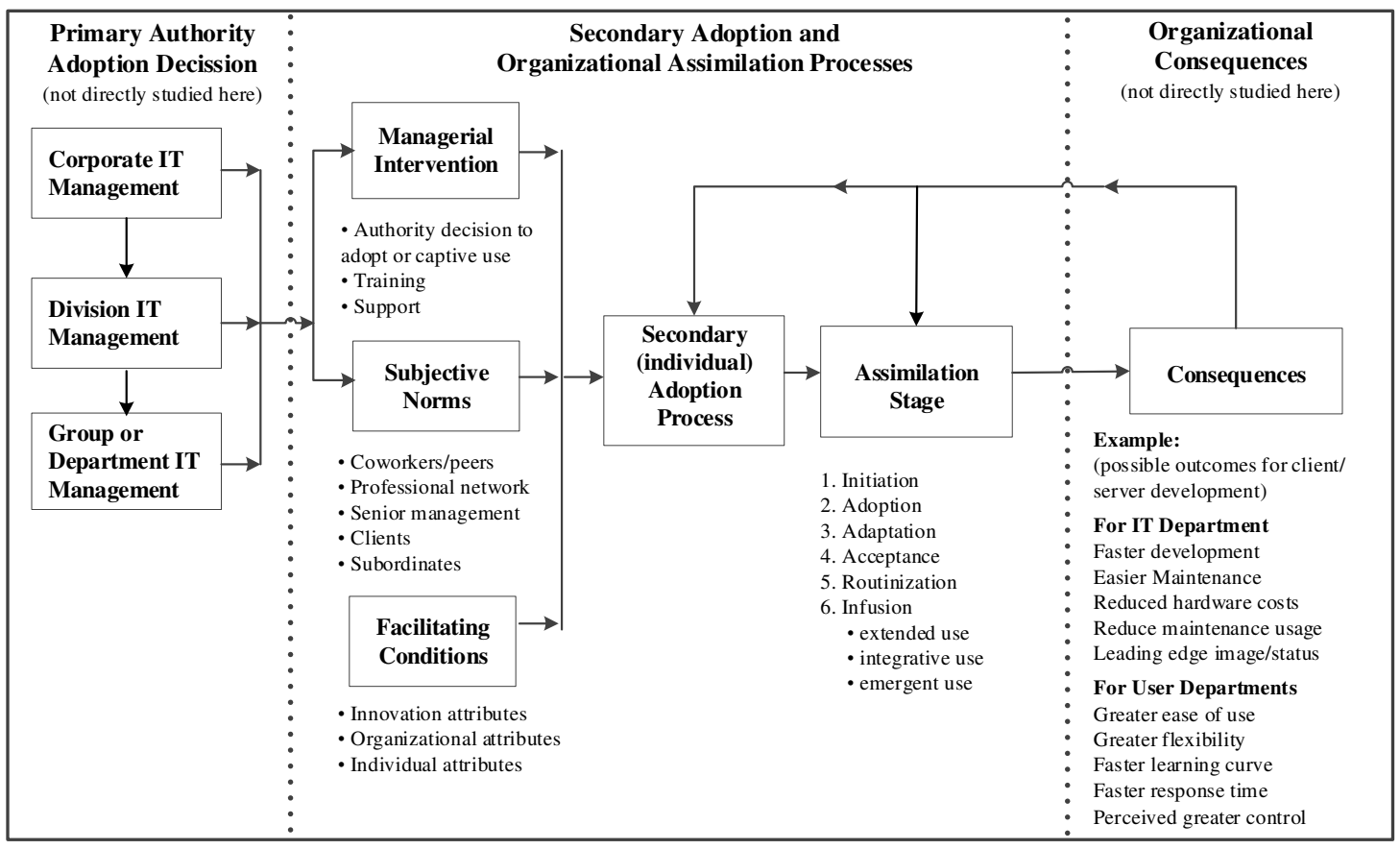

Figure 1. Framework for Innovation Adoption and Implementation (Gallivan, 2001b, p. 60)

The vertical dotted lines separate the framework into three segments, namely primary adoption decision, secondary adoption and organisational assimilation processes, and organisational consequences (Gallivan, 2001b). The first segment describes the primary adoption decision by the managers, either at the corporate, division or department level of the organisation. The second segment explores the secondary adoption and the assimilation processes after the primary innovation adoption decision is made. The last segment focuses on the implementation consequences. The reverse arrows from "organisational consequences" 
back to "assimilation stage" and to "secondary adoption process" indicate the complexity and the dynamic process of implementation (Gallivan, 2001b).

Following the primary adoption by the managers, several mediating factors (i.e. managerial interventions, subjective norms, and facilitating conditions) will emerge to influence the secondary adoption process by the employees. The managerial interventions describe "the actions taken and resources made available by managers to expedite secondary adoption, including mandating usage" (Gallivan, 2001b, p. 61). These interventions may comprise of training, support, and resources made available by the managers to accelerate the secondary adoption by the employees. The subjective norms construct describes "individuals' belief about the expectation of relevant others regarding their own secondary adoption behaviour" (Gallivan, 2001b, p. 61). The facilitating conditions construct is "a broad category that captures other factors that can make implementation more- or less-likely to occur" (Gallivan, 2001b, p. 61) and comprises of innovation, organisational, and individual attributes.

In a scenario of contingent authority innovation-decision, the issue is "not whether employees adopt the innovation (since this is assumed), but rather when and how they adopt it -- through what experiences, with what obstacles encountered, and how these events influence organizational assimilation and outcomes" (Gallivan, 2001b, p. 62).

To provide a state-of-the-art landscape of research in higher education, a review was also conducted on previous ICT studies in several countries with regard to this context. This is presented in the next section.

\subsection{ICT Studies in Higher Education Institutions}

Table 1 presents a review of state-of-the-art ICT studies conducted within the context of higher education institutions in several countries.

\begin{tabular}{|c|l|l|l|l|}
\hline No & $\begin{array}{c}\text { Author } \\
\text { (Year), } \\
\text { Country }\end{array}$ & \multicolumn{1}{|c|}{$\begin{array}{c}\text { Research Topic, ICT Artefact, } \\
\text { Voluntariness }\end{array}$} & \multicolumn{1}{|c|}{ Source of Data } & \multicolumn{1}{|c|}{ Key Findings } \\
\hline 1 & $\begin{array}{l}\text { Al-Shboul, } \\
\text { Al-Saideh, } \\
\text { \& Al- } \\
\text { Labadi } \\
(2017), \\
\text { Jordan }\end{array}$ & $\begin{array}{l}\text { Examining the perceptions and } \\
\text { barriers concerning the use of ICT } \\
\text { tools by students in Jordanian } \\
\text { Universities }\end{array}$ & $\begin{array}{l}\text { Survey of 725 } \\
\text { students from } 4 \\
\text { Jordanian } \\
\text { Universities }\end{array}$ & $\begin{array}{l}\text { Positive perceptions of } \\
\text { students towards ICT in } \\
\text { higher education }\end{array}$ \\
\hline 2 & $\begin{array}{l}\text { Chaputula } \\
\text { (2012), } \\
\text { Malawi }\end{array}$ & $\begin{array}{l}\text { Examining the voluntary adoption } \\
\text { of simple ICT innovations (word } \\
\text { processor, internet, laptop and } \\
\text { mobile phone) for teaching, } \\
\text { research and internet browsing }\end{array}$ & $\begin{array}{l}\text { Survey of 317 } \\
\text { students and 113 } \\
\text { academic staff and } \\
\text { one librarian }\end{array}$ & $\begin{array}{l}\text { Poor infrastructure and lack } \\
\text { of ICT skills, high cost of } \\
\text { internet access and } \\
\text { persistent power outages }\end{array}$ \\
\hline 3 & $\begin{array}{l}\text { Huda \& } \\
\text { Hussin } \\
\text { (2010), } \\
\text { Indonesia }\end{array}$ & $\begin{array}{l}\text { Examining the implementation } \\
\text { barriers of ICT in general } \\
\text { (administration, teaching, learning } \\
\text { and research) }\end{array}$ & $\begin{array}{l}\text { Interviews of 2 top- } \\
\text { level university } \\
\text { executives }\end{array}$ & $\begin{array}{l}\text { The main inhibitors are } \\
\text { work culture and } \\
\text { individual perception } \\
\text { towards ICT }\end{array}$ \\
\hline
\end{tabular}




\begin{tabular}{|c|c|c|c|c|}
\hline No & $\begin{array}{l}\text { Author } \\
\text { (Year), } \\
\text { Country }\end{array}$ & $\begin{array}{c}\text { Research Topic, ICT Artefact, } \\
\text { Voluntariness }\end{array}$ & Source of Data & Key Findings \\
\hline 4 & $\begin{array}{l}\text { Meerza \& } \\
\text { Beauchamp } \\
(2017), \\
\text { Kuwait }\end{array}$ & $\begin{array}{l}\text { Examining the critical factors for } \\
\text { the use of general ICT to support } \\
\text { learning at universities }\end{array}$ & $\begin{array}{l}\text { Structured } \\
\text { questionnaire and } \\
\text { interviews of } \\
\text { undergraduate } \\
\text { students }\end{array}$ & $\begin{array}{l}\text { Usefulness, ease of use of } \\
\text { ICT, and peer learning as } \\
\text { key factors for ICT } \\
\text { utilisation }\end{array}$ \\
\hline 5 & $\begin{array}{l}\text { Othman, } \\
\text { Pislaru, } \\
\text { Kenan, \& } \\
\text { Impes } \\
\text { (2013), } \\
\text { Libya }\end{array}$ & $\begin{array}{l}\text { Examining the usage of simple ICT } \\
\text { innovations (tools used for online } \\
\text { learning, virtual classroom and e- } \\
\text { module) for student learning } \\
\text { activities }\end{array}$ & $\begin{array}{l}\text { Open and closed- } \\
\text { ended } \\
\text { questionnaire }\end{array}$ & \begin{tabular}{|l} 
Support staff needed to \\
reduce academic staff's \\
burden, a fixed budget to \\
maintain and develop ICT, \\
training and incentives for \\
staff
\end{tabular} \\
\hline 6 & $\begin{array}{l}\text { Setiawan } \\
(2012), \\
\text { Indonesia }\end{array}$ & $\begin{array}{l}\text { Examining the implementation } \\
\text { barriers and challenges for ICT in } \\
\text { general }\end{array}$ & $\begin{array}{l}\text { Interviews of } 20 \\
\text { staff, informal } \\
\text { discussion and } \\
\text { document } \\
\text { collection in a } \\
\text { university }\end{array}$ & $\begin{array}{l}\text { Limited human resources, } \\
\text { lack of management } \\
\text { commitment, funding and } \\
\text { rewards and ineffective } \\
\text { communication and } \\
\text { coordination }\end{array}$ \\
\hline 7 & $\begin{array}{l}\text { Shaikh } \\
(2009), \\
\text { Pakistan }\end{array}$ & $\begin{array}{l}\text { Examining the role and voluntary } \\
\text { usage of simple ICT innovations } \\
\text { (Ms Office, Google) in teaching and } \\
\text { learning }\end{array}$ & $\begin{array}{l}\text { Survey to } 30 \text { faculty } \\
\text { members, students, } \\
\text { parents, admin } \\
\text { staff, and ICT } \\
\text { policy makers }\end{array}$ & $\begin{array}{l}\text { Lack of training for } \\
\text { teaching / support staff, } \\
\text { poor infrastructure, and } \\
\text { lack of effective ICT policy }\end{array}$ \\
\hline 8 & \begin{tabular}{|l} 
Wilson, \\
Tete- \\
Mensah, \& \\
Boateng \\
$(2014)$, \\
Ghana
\end{tabular} & $\begin{array}{l}\text { Examining the voluntary usage of } \\
\text { simple ICT innovations (mobile } \\
\text { phones, TV, radio, PC, laptop, } \\
\text { digital camera, voice recorder) for } \\
\text { student's personal learning }\end{array}$ & $\begin{array}{l}\text { Questionnaire to } \\
500 \text { students and } \\
\text { focus-group } \\
\text { discussion in a } \\
\text { Ghana University }\end{array}$ & $\begin{array}{l}\text { Students and teachers have } \\
\text { low technology literacy } \\
\text { skills and training is needed }\end{array}$ \\
\hline
\end{tabular}

Table 1. Previous ICT Studies in the Context of Higher Education

The review indicated that research focusing on the mandated adoption of innovations in the context of higher education institutions is scarce. The focus of the research was more towards the identification of challenges and barriers for ICT usage in higher education institutions (AlShboul, Al-Saideh, \& Al-Labadi, 2017; Huda \& Hussin, 2010; Meerza \& Beauchamp, 2017; Setiawan, 2012) and the voluntary and non-contingent adoption of simple innovations (i.e. PC, laptop, internet, and office applications) (Chaputula, 2012; Othman et al., 2013; Shaikh, 2009; Wilson et al., 2014).

The issue of mandatoriness was often taken for granted in previous studies and yet it may prove to be significant in influencing the subsequent adoption of the innovations by the users (Brown et al., 2002; Gallivan, 2001b). Therefore the researcher chose to explore the AIS as it was considered to be a complex ICT innovation that posed challenges due to its contingent nature and its mandated adoption in the University. As the AIS was introduced to the academics in 2012, this research was able to assess its uptake, as sufficient time had passed for it to be assimilated into the University. 
The following section presents the preliminary conceptual framework that was chosen and used in this research.

\subsection{Preliminary Conceptual Framework}

Based on the analysis of previous studies, Gallivan's (2001b) framework for innovation adoption and implementation was chosen as a theoretical lens to explore the case in this research. The qualitative nature of the framework has a degree of flexibility to anticipate novel findings with regard to the factors that may influence innovation adoption and implementation.

However applying the framework was challenging as the specific arrangement and timing for when the factors begin to give influence were not specifically addressed by Gallivan (2001b). Moreover, the context of the case and the nature of the innovation in this research was different from those of Gallivan. For example, Gallivan focused his investigation on insurance firms in the United States, while this research focuses on a university in Indonesia. In terms of the innovation, Gallivan's research investigated the adoption of a client/server development software that was purchased commercially, while this research explored the adoption of an academic information system that was developed in-house.

Framework modifications were needed to address the challenge and the differences. Venkatesh and Bala's (2008) 'research agenda for interventions', which was also inspired by the IT implementation process (Cooper and Zmud, 1990), were considered useful for the modification of the framework. The modified framework is illustrated in Figure 2.

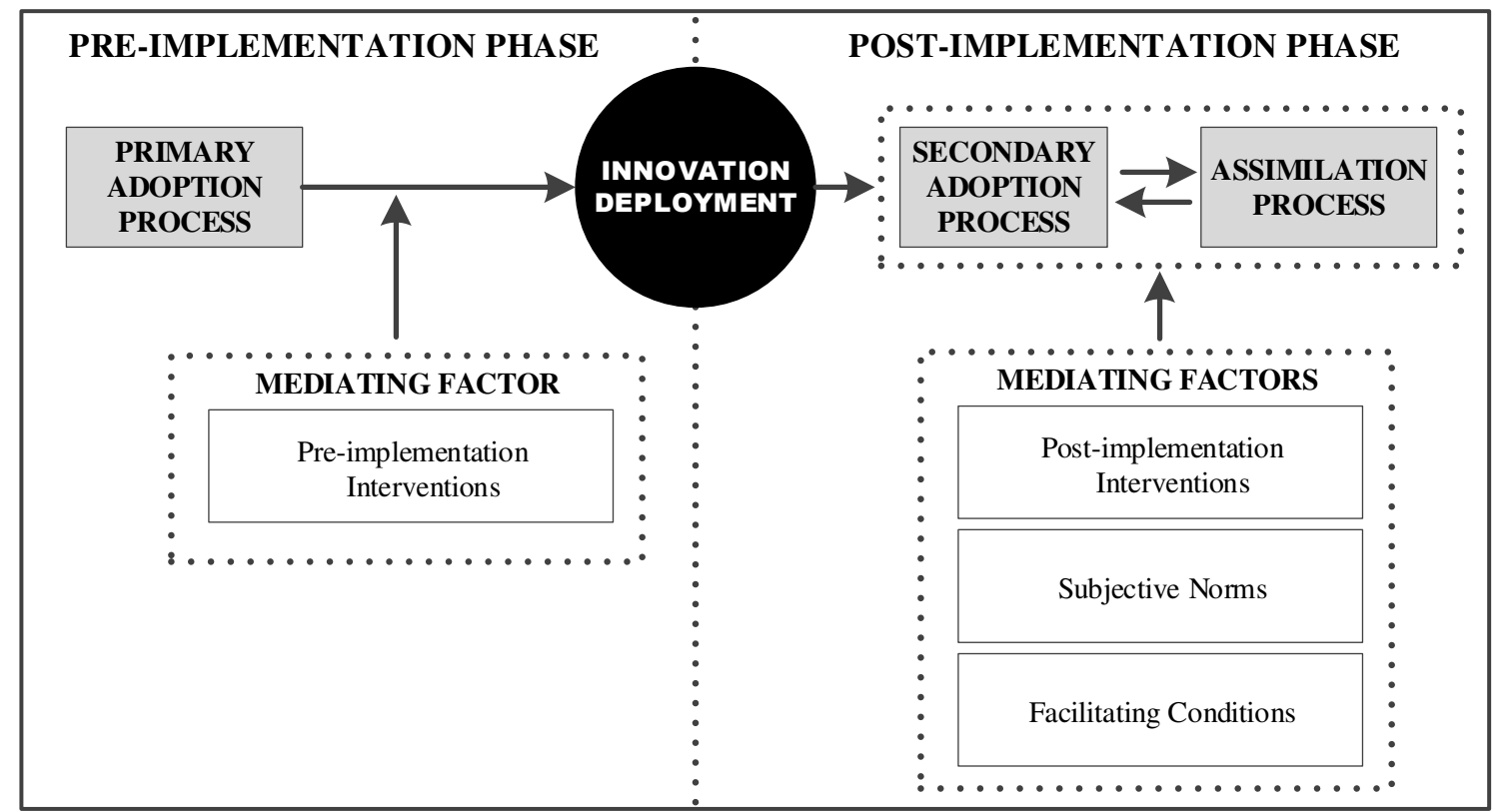

Figure 2. Modified Framework for Innovation Adoption and Implementation (Based on Gallivan, 2001b; Venkatesh E Bala, 2008)

The modified framework consists of two phases: pre-implementation (prior to innovation deployment) and post-implementation (after innovation deployment). Three main processes occurred during these phases: primary adoption process, secondary adoption process, and assimilation process. 
The pre-implementation phase describes the decisions and actions made by the managers during the initial implementation of the innovation, which involves the primary adoption process and the mediating factors (i.e. managerial interventions). The post-implementation phase highlights the perspectives and experience of the employees as the secondary adopters of the innovation, which includes the secondary adoption process, the assimilation process, and several mediating factors (post-implementation interventions, subjective norms, and facilitating conditions).

The primary adoption process describes the initial decision made by the managers as the primary adopters of the innovation. To support secondary adoption by the employees, the pre-implementation interventions are deliberately provided by the managers. In the secondary adoption process, employees start to play their role as secondary adopters of the innovation. The assimilation process highlights the use of the innovation by the employees as it assimilates into the organisation. The reverse arrows from "assimilation process" back to "secondary adoption process" indicate the dynamic process of implementation (Gallivan, 2001b).

By incorporating individual and organisational levels of analysis, the framework examines the innovation adoption and implementation using the multilevel perspectives of the actors involved (Burton-Jones \& Gallivan, 2007; Gallivan, 2001a). By so doing, the research can provide organisation managers with a deeper understanding of the case and assist them in making informed decisions with regard to innovation implementation.

The methodology of the research is outlined in the next section.

\section{Methodology}

This research took an interpretivist approach by utilising constructivism as its philosophical grounding (Williamson \& Johanson, 2013). Utilising this approach, collective meanings were constructed from the research participants by taking account of the norms and values embedded in their beliefs, decisions, and actions with regard to the case being studied (Myers, 2013; Orlikowski \& Baroudi, 1991; Walsham, 2006; Williamson \& Johanson, 2013).

Figure 3 illustrates the research design that was used as a guide during the course of this study.

The aim and questions of the research drove the research theme to focus on the literature concerning organisational innovation studies of information systems and ICT studies in higher education institutions. A mixed approach literature review was used in this research as the researcher had already decided the research theme prior to commencing the review with the purpose of gaining a thorough understanding of the literature (Bandara, Furtmueller, Gorbacheva, Miskon, \& Beekhuyzen, 2015; Boell \& Cecez-Kecmanovic, 2015).

The case study research method was utilised, as it was considered appropriate to accommodate the focus on human interpretations and meanings, with regard to the phenomenon being studied (Eisenhardt, 1989; Walsham, 1995). The single case design was specifically chosen because it accommodates the focus on the breadth and depth of the case (Yin, 2014) and provides a richer understanding and lessons-learned information from the experience of the actors and the organisation (Creswell, 2013; Stake, 1995). 


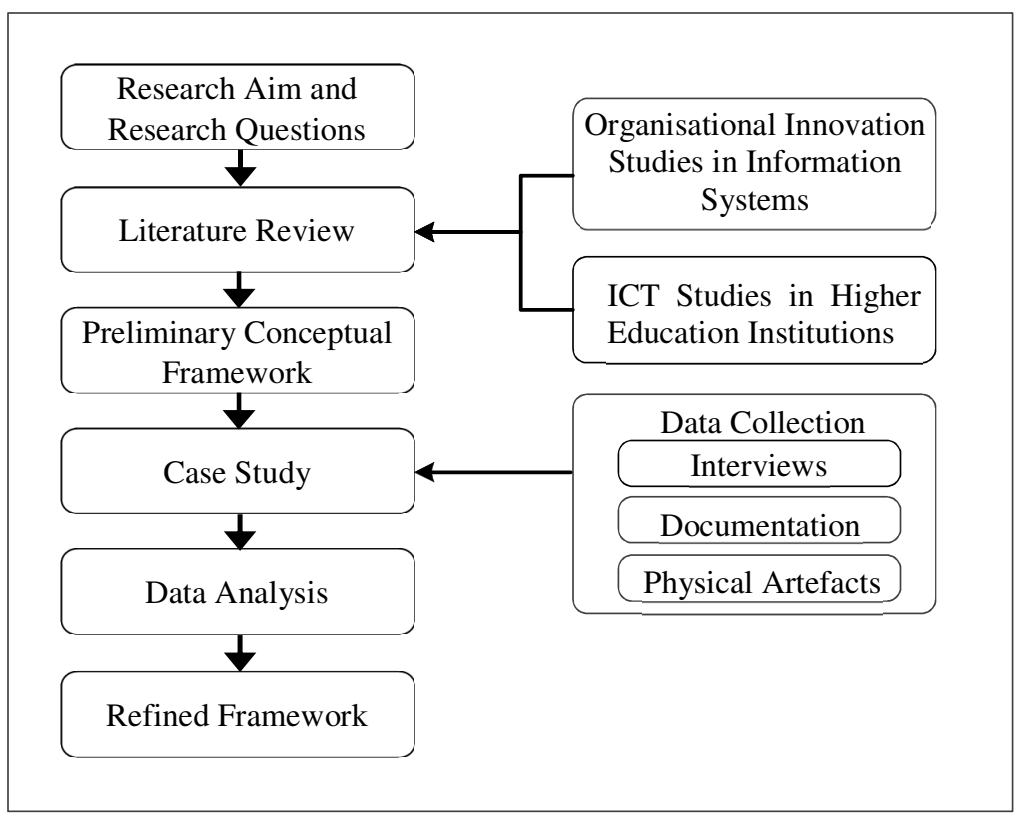

Figure 3. Research Design

The main technique used in this research was semi-structured interviews, supported by documentation and physical artefacts (Yin, 2014). Interviews were undertaken at the Indonesian university in November-December 2015. These techniques are elaborated on below.

\section{Semi-structured Interviews}

The semi-structured interview was used to accommodate research questions based on the preliminary conceptual framework. The use of this technique brought benefits to the researcher as it encouraged two-way communication and allowed new perspectives and ideas to emerge during interviews. A general overview of the participants is presented in Table 2.

\begin{tabular}{|c|c|c|c|c|c|c|}
\hline & & \multicolumn{4}{|c|}{ Participant } & \multirow{3}{*}{ Total } \\
\hline & & \multirow[b]{2}{*}{ Academics } & \multirow[b]{2}{*}{ Executives } & \multicolumn{2}{|c|}{ Administrative Staff } & \\
\hline & & & & $\begin{array}{c}\text { Head of } \\
\text { Administration }\end{array}$ & $\begin{array}{c}\text { Staff } \\
\text { Member }\end{array}$ & \\
\hline \multirow{5}{*}{ Level } & University & - & 5 & 3 & 1 & 9 \\
\hline & Faculty A & 3 & - & 1 & - & 4 \\
\hline & Faculty B & 6 & - & 1 & 1 & 8 \\
\hline & Faculty C & 4 & - & - & 2 & 6 \\
\hline & Faculty D & 6 & - & - & 1 & 7 \\
\hline \multicolumn{2}{|c|}{ Total } & 19 & 5 & 5 & 5 & 34 \\
\hline
\end{tabular}

Table 2. Interviewed Participants at the University 
The interviews were carried out with 34 stakeholders from three categories: the university academics (19 participants), the top-level university executives (five participants), and the administrative staff (ten participants). Each of the categories had different roles and therefore was given a different set of questions during their interviews. A relatively balanced number of academics were sought from four faculties, based on gender and age, to ensure a fair representation across the spectrum. The five top-level executives who were interviewed included Vice-Rector A, Vice Rector B, the Director of ICT, the Head of the ICT Centre, and the Head of Quality Assurance. The interviews lasted 30-60 minutes each, were conducted using the Indonesian language, and were all audio-recorded.

\section{Documentation}

The documentary evidence collected during this research was in the form of online and offline documents. The online documents were retrieved from the official website and two blogs maintained by the University. The offline documents were obtained from three books, two decrees, two written policies, and one statistical report of the University. The results from the documentation were then used to provide a contextual account of the case being studied and to corroborate the information from the interviews.

\section{Physical Artefacts}

An exploration of the physical artefacts was needed as the case involved a transformation from the previous system to a new system. Physical artefacts from the previous system were the Optical Scanners, which were used to scan forms in the previous paper-based system. The artefact which was considered as the innovation was the Academic Information System.

The researcher paid particular heed to Klein and Myers' (1999) principle of multiple interpretations and principle of dialogical reasoning in designing the study. There were very different and at times contradictory perspectives from the participants (i.e., the executives and the academics); and the preliminary framework was constantly refined based on the findings.

Figure 4 illustrates the method for data analysis for this research. To acquire valid meaning from the qualitative data, the method of analysis as advocated by Miles, Huberman, and Saldaña (2014) and Saldaña (2015) was employed.

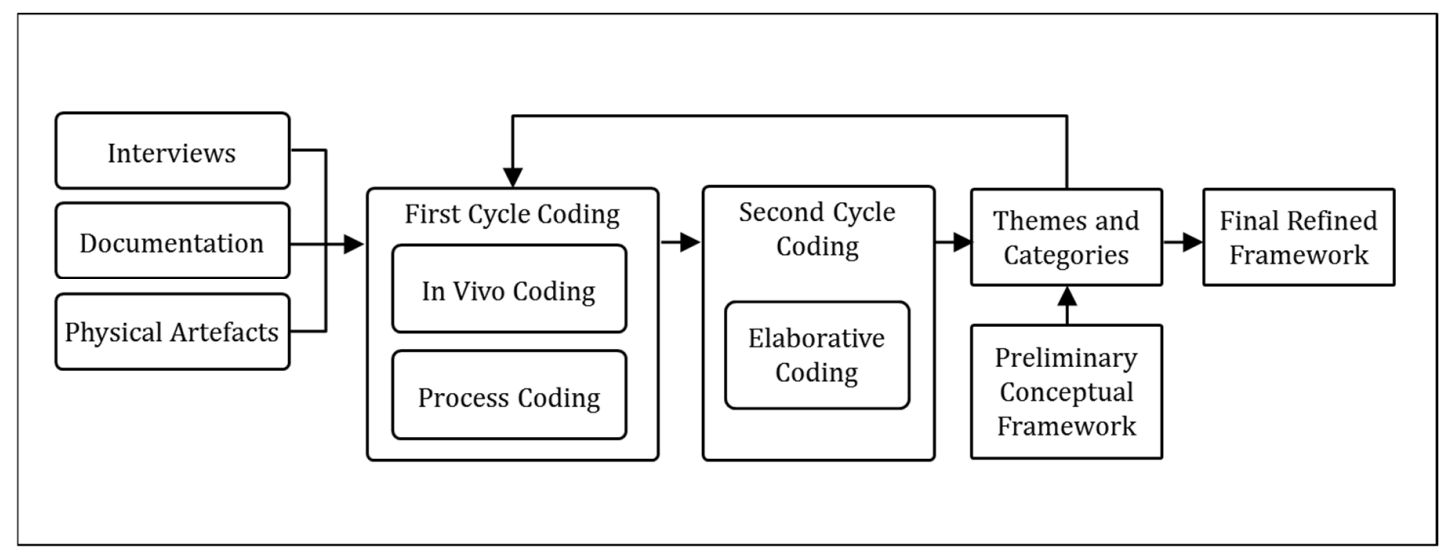

Figure 4. Method for Data Analysis

The coding stage was divided into the first cycle and second cycle coding as the data sources were analysed using thematic analysis. 'In vivo coding' and 'process coding' methods were employed during the first cycle coding (Saldaña, 2015). "In vivo coding" (i.e. not to be 
confused with the NVivo Software), also known as "verbatim coding", is a method of analysis that is used to extract the participants' own terms as the source for codes (Miles et al., 2014; Saldaña, 2015). The use of the "process coding" method assisted the researcher in compiling codes based on the activities shown and described by the interview participants (Saldaña, 2015). As the researcher was guided by a preliminary framework, 'elaborative coding' was selected as the second cycle coding method, as this method not only preserves the themes and categories from the preliminary framework, but also allows new themes and categories to emerge during the data analysis (Miles et al., 2014; Saldaña, 2015).

\section{Results}

This section presents findings with regard to the mandated adoption and implementation of the AIS, which is structured based on the preliminary conceptual framework. Based on the results of the first and second cycle coding of events occurring in the pre- and postimplementation phases, details regarding the primary adoption, secondary adoption, assimilation processes, and the mediating factors are provided.

\subsection{Pre-implementation Phase}

This phase explored the decisions and actions, as envisaged by five university executives, who were involved as the decision makers in the pre-implementation phase of the AIS at the University. Information was also retrieved from the administrative staff to substantiate details at the operational level, which could not be provided by the executives.

\subsubsection{Primary Adoption Process}

The thematic analysis for the primary adoption process focused on the interviews conducted with five executives and ten administrative staff at the University (Figure 5).

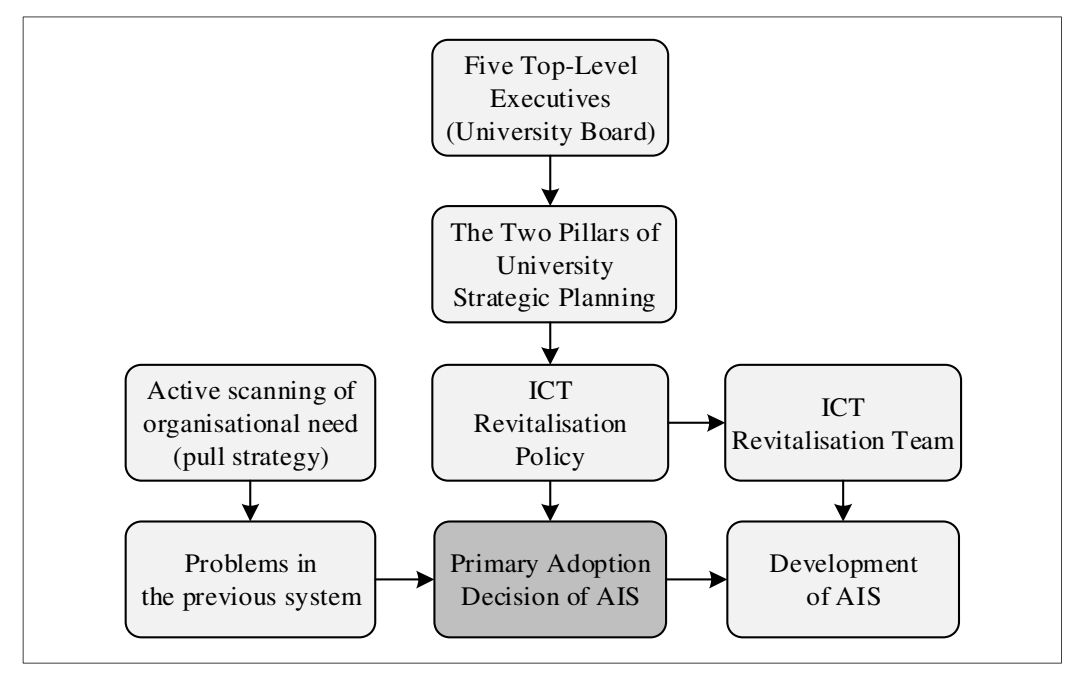

Figure 5. Process of the Primary Adoption

The major themes surrounding the primary adoption of the AIS were highlighted with problems in the previous paper-based system, such as grade manipulation and lengthy procedures. The problems were exacerbated with the increase in the number of university stakeholders. 
There used to be a long delay for the students' grade submissions in the faculties. Grade manipulation was also possible. People other than the relevant academics were handling the students' grade forms and the final output sometimes did not match with the grades given by the academics. It happened everywhere. (Vice-Rector B)

With regard to the initial decision to adopt the AIS, the result of the analysis showed that it was made solely by the executives as a part of an ICT Revitalisation Policy.

We viewed it as a demand for technology. In such cases, we don't really need to consult with the academics. The meetings held by the University Board were enough to decide its adoption. (Head of Quality Assurance)

With regard to the adoption of AIS for the academics, mandatoriness was a clear theme as the phrase "whether you want it or not" was used repeatedly during the interviews.

For the AIS, it is clearly mandatory. It is obligatory. It is a must whether you want it or not because it is a portal that you have to pass through. (Director of ICT)

As the University is owned and operated by the government, its bureaucratic and paternalistic culture inherited a hierarchical structure, in which the executives had the right to impose decisions that impacted the routine tasks of the academics, who were seen to have lower rank (Asian Development Bank, 2012; Boyne, 2002; Rogers, 2003).

The next section describes the interventions given by the executives to support the adoption of the AIS by the academics.

\subsubsection{Pre-implementation Interventions}

Once the decision was made by the top-level executives to implement the AIS, the preimplementation process was set in motion. A considerable amount of the budget was invested in the ICT infrastructure and human resources as forms of managerial interventions.

A large portion of our budget is directed towards ICT: to develop ICT, to increase the bandwidth, and so on. We also encourage the addition of ICT staff. (Vice-Rector B)

Based on the analysis of the interviews, several codes were identified as managerial interventions during the pre-implementation of the AIS, as listed in Table 3.

\begin{tabular}{|l|l|l|}
\hline No & \multicolumn{1}{|c|}{ Interventions } & \multicolumn{1}{c|}{ Execution Level } \\
\hline 1 & AIS Development, User Manual, and Online Helpdesk & University Level \\
\hline 2 & Dissemination Seminars & University Level \\
\hline 3 & AIS Championing & University Level \\
\hline 4 & Infrastructure Support & University Level \\
\hline 5 & Usage Mandate & University Level \\
\hline
\end{tabular}

Table 3. Pre-implementation Interventions

The AIS was developed in-house by the ICT Centre of the University to ensure there was flexibility to modify the AIS when needed at a future time. The user manual and online helpdesk were provided and embedded in the functions of the AIS. Following the development of the AIS, a dissemination seminar was conducted as the first attempt to properly introduce the AIS to the academics. 
We presented it (AIS) to the academics in the form of dissemination seminars and by listing the shortcomings that have not yet been addressed based on their demands. (Director of ICT)

The Director of ICT in particular, with his legitimacy and ICT competency, exhibited transformative leadership and played an influential role among the executives, the academics, and the staff. Prior research has acknowledged the importance of using champions during the adoption and implementation of complex innovations (Beath, 1991; Chatterjee, Grewal, \& Sambamurthy, 2002; Jasperson, Carter, \& Zmud, 2005; Leonard-Barton, 1988; Norris, 1999; Purvis, Sambamurthy, \& Zmud, 2001; Taylor \& Todd, 1995).

\subsection{Post-implementation Phase}

This section focuses on the analysis of the perspectives and experiences of the academics as they began to adopt and use the AIS. Information from the executives and the administrative staff of the University are also presented to substantiate the findings.

\subsubsection{Secondary Adoption and Assimilation Processes}

The high level of resistance from the academics became a major theme following the deployment of the AIS. The Head of the ICT Centre confirmed that resistance was expressed in the form of protests and complaints to the executives and the staff at the ICT Centre.

For the AIS, there was a large amount of resistance when it was first introduced due to the transition from manual or semi-digital to fully digital. The resistance was in the form of protests and complaints. (Head of the ICT Centre)

Figure 6 illustrates the result of coding with regard to the cause of the resistance by the academics during the secondary adoption process.

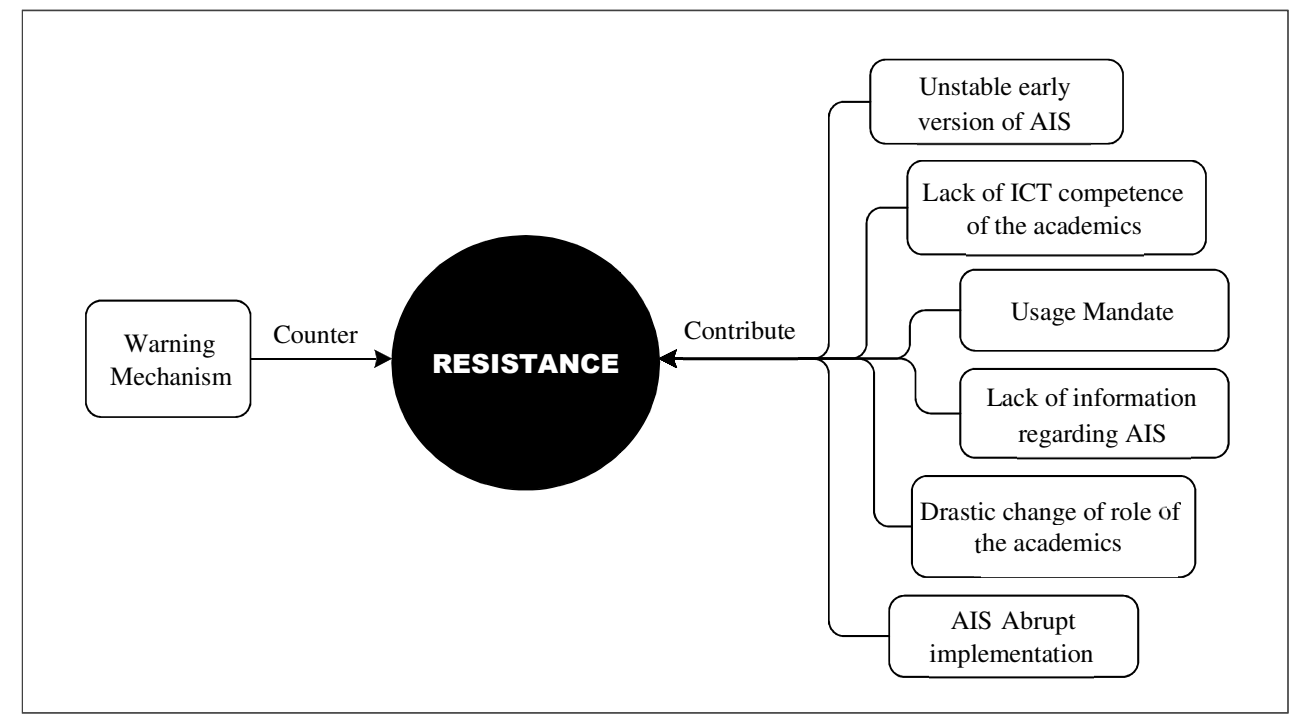

Figure 6. Resistance in the Secondary Adoption Process

Based on further analysis of the interviews with the academics, ineffectiveness was found to be a major theme for the pre-implementation interventions as the academics were not given sufficient information and skills to operate the AIS prior to its deployment. Together with the usage mandate enforced by the executives, the ineffective pre-implementation interventions placed a larger burden on the post-implementation interventions. During data coding, the 
phrase "whether we like it or not" was also repeatedly uttered by the academics during interviews, implying that they were not given any choice but to adopt the AIS.

The AIS was made mandatory from the institution, so whether we like it or not, all academics must use it. (Academic 10, male, Faculty C)

Other causes contributing to the resistance included the lack of information regarding the AIS, the abrupt implementation of the AIS, the unstable early version of the AIS, the academics' lack of ICT competence, and their drastic change of role (from passive to active users).

There was no information. We only knew about it from the dissemination seminar. We did not know about it beforehand. (Academic 10, male, Faculty C)

It was abruptly implemented and we had to use it. (Academic 3, male, Faculty A)

Surprisingly, the lack of participation and involvement of the academics in the primary adoption decision tended to be tolerated as they were already used to such a decision-making process.

I choose to see it this way. The decision has been made and it is obligatory, it has to be done. (Academic 16, male, Faculty D)

Due to the high resistance, the usage mandate was then substantiated via a warning mechanism for the academics who delayed or resisted the use of the AIS. This involved the faculties sending warning letters to academics who failed to finish their task using the AIS by a given deadline, with an escalation procedure starting from the heads of department up to the faculty deans. This mechanism was proven to be effective in countering the resistance, as sanctions that impacted their wellbeing as civil servants would be given if they continued to oppose.

Those who have not submitted will receive a letter from the head of the department to immediately proceed with the submission. The department will contact the academics regarding that matter. If the head of the department cannot solve it, we would escalate the problem to the Vice-Dean and let him take care of the matter. Usually, the problem is resolved once it reaches the Vice-Dean. (Staff 5, male, Faculty A)

In the end, the warning mechanism was able to counter the high resistance demonstrated by the academics. All of the academics claimed to have adopted the AIS, although two main methods of usage were captured: direct and indirect. Out of the 19 academics, 17 were found to directly use the AIS. Although mostly dominated by younger academics, three senior academics who used the AIS directly were found to have had an informal ICT background as they were either educated abroad or had ICT-related experience.

Two academics used the AIS indirectly by delegating its use to four categories of surrogate: fellow academics, administrative staff, teaching assistants, and family relatives. The main reason for use delegation was low ICT competence due to the age factor and limited ICT background.

For the grade submission, I rely on my teaching assistant. My assistant was the one doing it for me. That's a real burden for me. (Academic 2, female, Faculty A)

Other reasons for delegating use included time constraints and laziness. The issue of power relation was also evident as some of the surrogates had no choice but to fulfil the request from the senior academics due to respect. 
The next section describes the interventions that emerged following the deployment of the AIS.

\subsubsection{Post-implementation Interventions}

During the data analysis, several codes related to post-implementation interventions emerged and are shown in Table 4.

\begin{tabular}{|c|l|l|}
\hline No & \multicolumn{1}{|c|}{ Interventions } & \multicolumn{1}{|c|}{ Execution Level } \\
\hline 1 & AIS Reinvention & University Level \\
\hline 2 & Dissemination Seminars and Training & Faculty A, C, and D \\
\hline 3 & AIS Championing & Faculty A and B \\
\hline 4 & Warning Mechanism & University Level \\
\hline 5 & Mentoring & Faculty A and B \\
\hline 6 & Peer Support & All Faculties \\
\hline
\end{tabular}

Table 4. Post-implementation Interventions

In the post-implementation phase, new interventions emerged such as training, mentoring, peer support, and the championing of the AIS by the Faculty Heads of Administration. These interventions were faculty-specific and were held without much coordination with the University.

The practice of mentoring was done by assigning academic staff as mentors, who provided personalised guidance concerning the AIS to the academics.

This faculty provides mentoring for the academics based on their departments. The purpose is so that we don't have to go too far to the ICT Centre for assistance. (Academic 5, male, Faculty B)

The mentoring in this research was associated with the technique of 'accompanying', in which the mentors made a commitment to guide the mentee side-by-side during the learning process (Aubrey \& Cohen, 1995). Such a practice was found to be effective especially in assisting senior academics in the University. Prior research suggested that mentoring facilitates the transfer of tacit knowledge that cannot be done effectively through formal training (Hsieh \& Hsu, 2013) and provides a flexible one-to-one approach that allows a longer time to adapt to new innovations (Gallivan, 2004).

It was also found that the academics felt more comfortable in seeking support from younger or tech-savvy fellow academics rather than formally forwarding their queries to the ICT Centre.

I studied it at first. I then asked my colleagues in case I bump into difficulties. We have 58 academics here. If any of us has figured out a solution, we will ask him. So it's collegial learning. (Academic 16, male, Faculty D)

The peer support in this research refers to a specific approach of conducting informal tutorials to support peers in the same organisation (Jasperson et al., 2005). Informal support from peers, as a form of 'help-seeking behaviour', is more preferred if compared to the formal support (Ram \& Jung, 1991). Other studies also found that such influence can enhance innovation implementation by forming favourable perceptions of an innovation and reduce anxiety towards it (Fiato, 2012; Venkatesh \& Davis, 2000). 
The findings also showed that the training for the AIS was not centralised in the University but instead was conducted in faculties based on their own initiatives. Although previous studies suggested that training is an important intervention (Gallivan, Spitler, \& Koufaris, 2005; Venkatesh \& Bala, 2008), interestingly it was not considered to be the main intervention as it was held with little or no coordination on the part of the University.

The role of Heads of Administration as faculty champions was found to be pivotal in the context of a mandated innovation adoption. Their legitimacy, access, and ICT competency, were found to reduce the negative impacts from the lack of coordination between the faculty and the university.

In general, the exploration of the multilevel perspectives of the participants revealed the different perspectives between the executives and the academics concerning the implementation of the AIS. The executives perceived it as part of a larger strategic plan of revitalising ICT in the University. However the usage mandate and other causes of resistance led the academics to perceive it as merely a radical switch from the previous system and thus influenced their willingness to adopt and use the AIS.

\section{Discussion}

This section discusses and explains the findings related to the mandated adoption and implementation of the AIS in the Indonesian University. Corresponding to the research questions, the nature of the adoption and implementation of the AIS is discussed in the preand post-implementation phases (Sections 5.1 and 5.2). The mediating factors and their influences towards the adoption of the AIS by the academics were also identified in these phases. Based on the findings in each of the phases, changes were made to the preliminary framework and resulted in the final refined framework presented in section 5.3.

\subsection{Pre-implementation Phase}

The pre-implementation phase includes the primary adoption process of the AIS, which led to its deployment (See Figure 7).

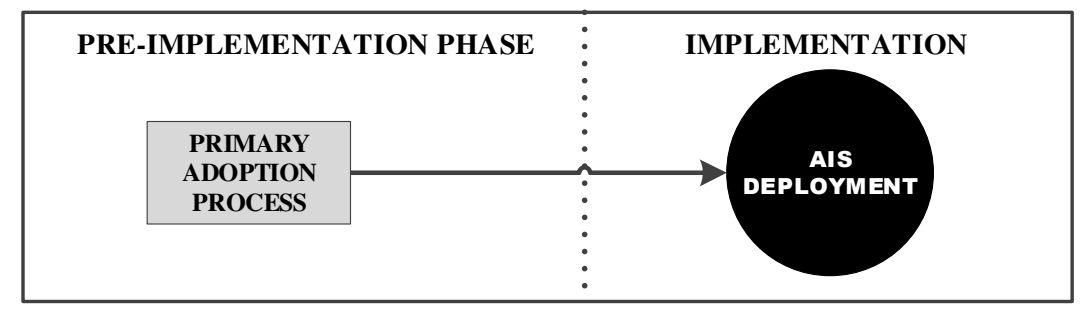

Figure 7. Pre-implementation Phase

Due to the bureaucratic and paternalistic culture of the University, the primary adoption process followed an authoritarian approach, as the initial adoption of the AIS was solely decided by the executives without involving the academics (Caudle, Gorr, \& Newcomer, 1991; Heintze \& Bretschneider, 2000; Zaltman et al., 1973). Two principal decisions were made by the executives during this process: the decision to adopt the AIS and the decision to mandate its usage.

The executives' authoritarian decision to adopt the AIS tended to be tolerated by the academics, as they were already accustomed to the paternalistic culture. However, the decision to mandate the use of the AIS for the academics was found to have more complex 
implications that significantly influenced the subsequent stages of implementation. To add to the pressure, the previous system was completely abandoned when the AIS was deployed, leaving no alternative for the academics but to adopt it.

During the pre-implementation phase, several mediating factors were identified and brought changes to the preliminary framework (See Figure 8).

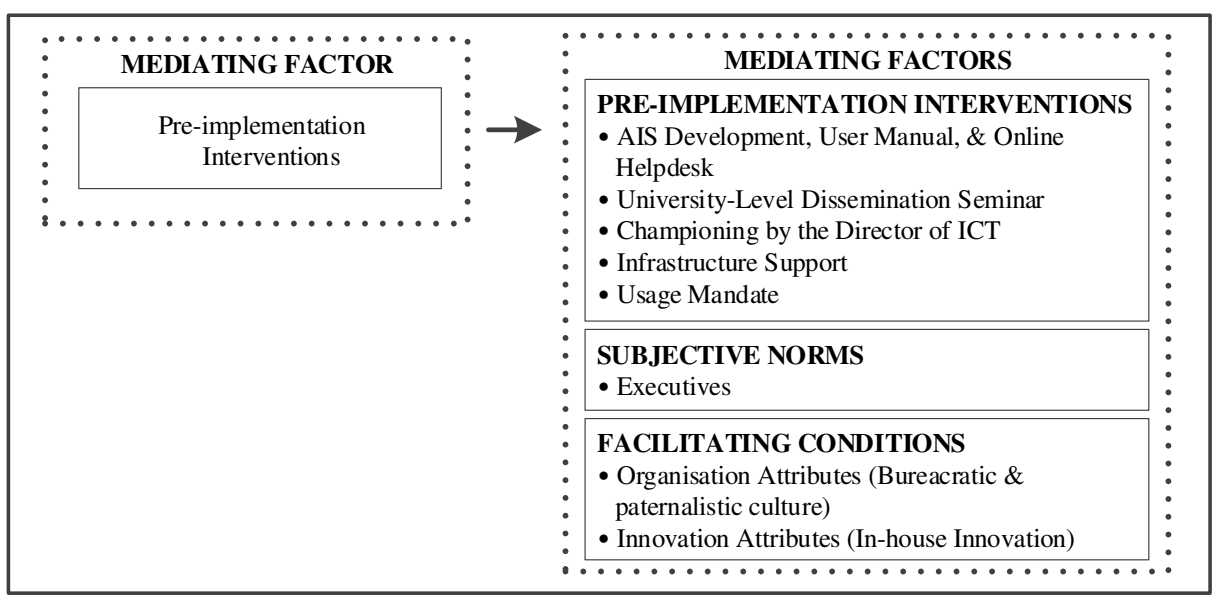

Figure 8. Changes in the Mediating Factors in the Pre-implementation Phase

Initially, the preliminary framework proposed pre-implementation interventions as the sole mediating factor in the pre-implementation phase. However the findings have captured other factors from the subjective norms and facilitating conditions constructs.

The pre-implementation interventions began with the development of the AIS with its user manual and online helpdesk as well as the provisioning of ICT infrastructure support. A university-level dissemination seminar was then provided to demonstrate the early version of the AIS to the academics and to highlight the usage mandate. A championing strategy was demonstrated by the Director of ICT to convince the academics with regard to the benefits of the AIS compared to the previous system.

The subjective norms construct was strongly demonstrated through the enforcement of the usage mandate and the warning mechanism for the academics to use the AIS. Organisational and innovation attributes emerged as facilitating conditions in this early phase of implementation. The bureaucratic and paternalistic culture defined the organisation attributes and affected the decision-making process in the University. The innovation attributes were made clear as the requirement for the AIS was to be developed in-house by the University.

\subsection{Post-implementation Phase}

The post-implementation phase outlines the processes that took place after the deployment of the AIS, namely the secondary adoption process and the assimilation process (See Figure 9).

The secondary adoption process was accompanied by resistance from the academics, mainly due to the usage mandate. However, the enforcement of the warning mechanism managed to counter the resistance and forced the academics to adopt the AIS. Thus the academics' decision to adopt was associated more with the effort to avoid the warning mechanism rather than their personal motivation to use the AIS (Brown et al, 2002). 


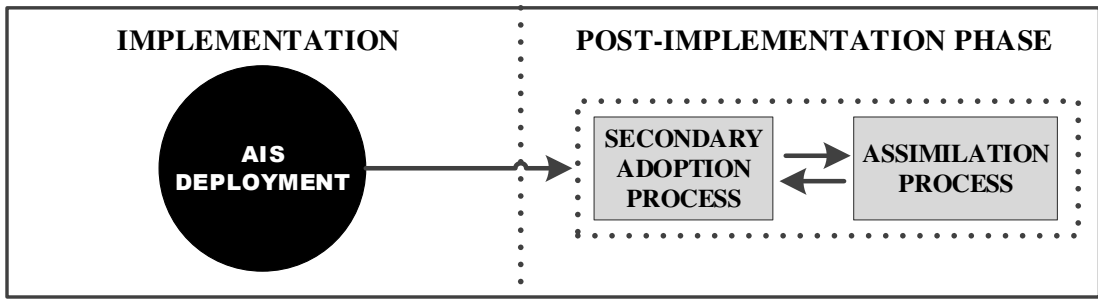

Figure 9. Post-implementation Phase

Following the adoption of the AIS by the academics, it began to be incorporated into the dayto-day tasks and signalled the beginning of the assimilation process (Gallivan, 2001b). The reverse arrow reflects the complex and dynamic process of the implementation, such as when the academics constantly adapt to the continuous enhancement of the AIS. Another example includes the difficulties for some of the senior academics in completely adopting the AIS. The negative implication of the mandate has resulted in the identification of two usage methods for the AIS: direct and indirect use (Burton-Jones \& Straub Jr, 2006; Tong, Teo, \& Tan, 2008).

According to Tong et al. (2008, p.2), direct use occurs when "a user independently uses an information system to accomplish an organisational task", while indirect use is defined as "the state in which a user employs an IS indirectly through one or more intermediaries (i.e., other colleagues) to accomplish an organisational task" (Tong et al., 2008, p.2). In the case of the AIS, most of the young and tech-savvy academics in the University used it directly while several senior academics decided to delegate its use to surrogates.

Several mediating factors were found to provide support during the assimilation of the AIS and brought changes to the preliminary framework as shown in Figure 10.

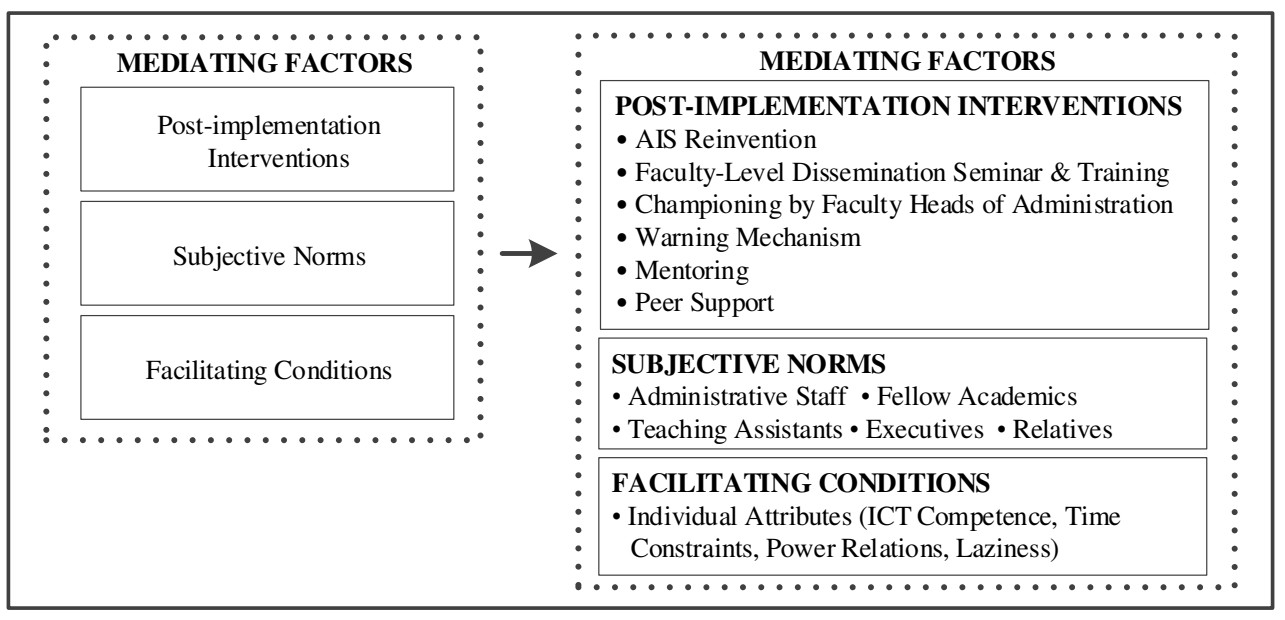

Figure 10. Changes in the Mediating Factors in the Post-implementation Phase

The post-implementation interventions consisted of AIS reinvention, faculty-level dissemination seminars and training, AIS championing, warning mechanism, mentoring, and peer support. Although the dissemination seminar had already been held at the university level, additional seminars and training were held at the faculty level to cope with its ineffectiveness. The AIS was refined gradually to accommodate requests from the executives and the academics. The cost of non-compliance was high, due to the enforcement of the warning mechanism for delaying or rejecting the use of the AIS. The role of Heads of 
Administration as local champions was regarded as vital in all of the faculties. In these faculties, informal peer support and mentoring were found to be effective in assisting academics with low ICT competence, as they required a longer time to adapt to the AIS.

The subjective norms construct demonstrated the influences coming from administrative staff, teaching assistants, executives, fellow academics, and family relatives in the form of warning mechanism, peer support, mentoring, and assistance in the use of the AIS. The facilitating condition construct is highlighted by the individual attributes of the university academics, including ICT competence, time constraints, power relations, and laziness.

The empirical evidence has brought changes to the preliminary conceptual framework. These changes are summed up and the final refined framework is presented in the following section.

\subsection{Final Refined Framework}

A contribution of this research to theory is by refining Gallivan's (2001b) framework based on the analysis of the findings. The final refined framework is shown in Figure 11.

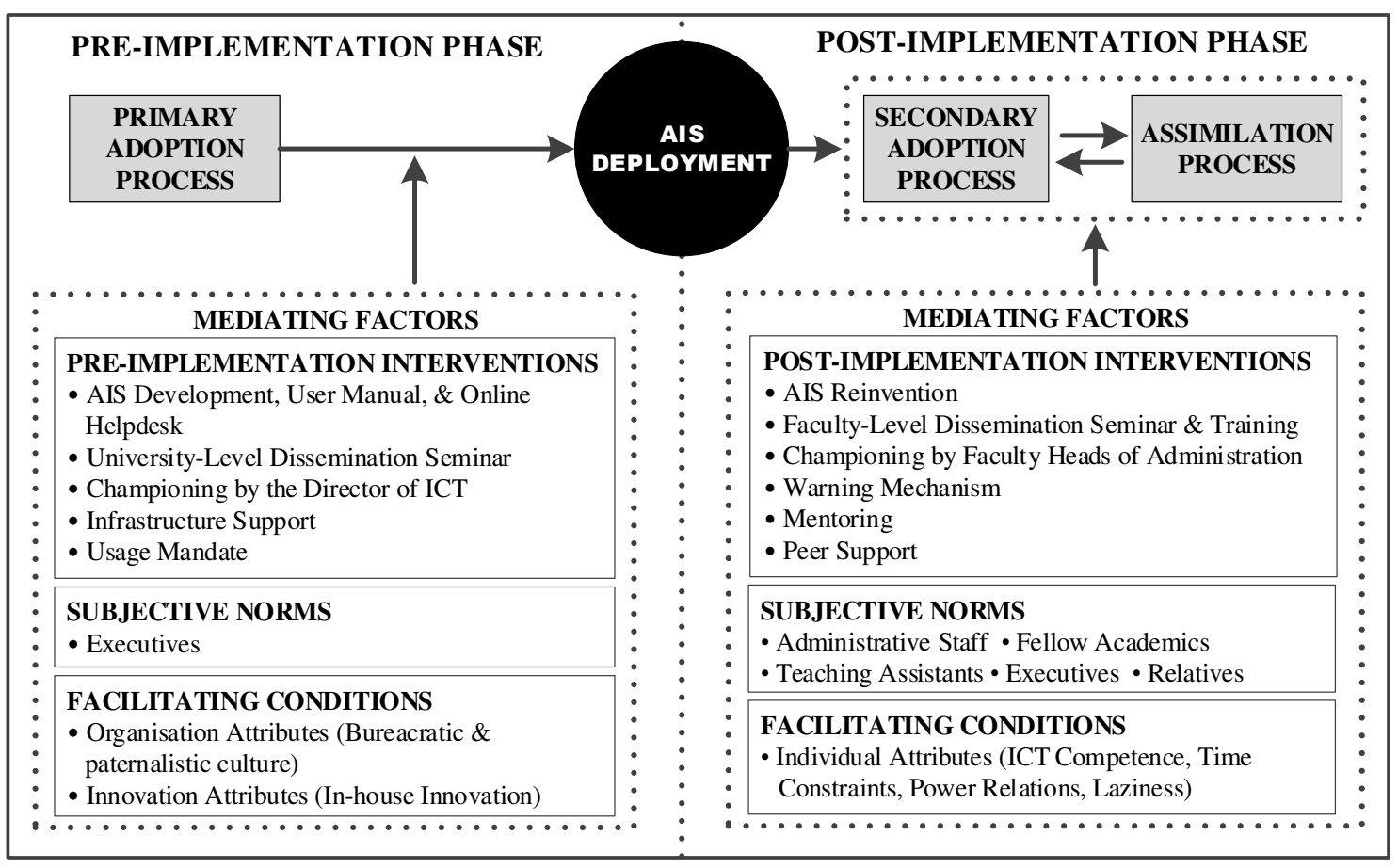

Figure 11. Final Refined Framework

Building upon the initial framework described in section 2.4, an exploration of the mandated adoption and implementation of the AIS in the Indonesian University was conducted. The findings confirmed that the adoption of the AIS followed the scenario of contingent authority innovation-decisions. As the primary adoption of the AIS was decided by the executives, a usage mandate and then later a warning mechanism were enforced on the academics.

The three constructs of the mediating factors (e.g. interventions, subjective norms, and facilitating conditions) were identified in the pre-implementation and post-implementation phases. Several interventions from the pre-implementation phase (e.g. AIS championing by the Director of ICT and infrastructure support) were continued in the post-implementation phase. Other interventions (e.g., the development of the AIS and the university-level 
dissemination seminar) were continued by similar interventions in the post-implementation phase (e.g., AIS reinvention and faculty-level dissemination seminars). In the postimplementation phase, several new faculty-specific interventions emerged without much coordination with the University, including mentoring, peer support, training, and AIS championing by Heads of Administration.

The subjective norms construct incorporates the sources of influence during the implementation of the AIS, which includes the executives, fellow academics, administrative staff, teaching assistants, and family relatives. Several facilitating conditions (e.g., organisation and innovation attributes) started to provide influences starting from the pre-implementation phase, while the influences from the individual attributes occurred later on, as the AIS began to be used by the academics.

\section{Conclusion}

Previous innovation studies were mostly dominated by quantitative studies that measure innovation acceptance by individuals in a social system. An investigation on mandated innovation adoption from the multilevel perspectives of the actors involved was needed as it may reveal the role of the usage mandate, managerial interventions and other influential factors.

A contribution of this research to theory is by modifying and then extending Gallivan's (2001b) framework based on the empirical evidence. As suggested in the final framework, the adoption of the AIS was associated with the scenario of contingent authority innovationdecision. The authoritarian approach during the pre-implementation phase was met with resistance and thus burdened the following phase of implementation. However the mediating factors identified in this research were found to play a pivotal role in reducing the resistance.

This research contributes to practice by providing insights to the university executives regarding the characteristics of the pre- and post-implementation managerial interventions that influenced the adoption of the AIS by the academics. The insights may assist the executives in evaluating their strategies for the current implementation of the AIS as well as in introducing future innovations.

Nonetheless as with any research, there are limitations to the study as it was based on data from just one higher education institution and focuses only on a single innovation. Future research can build upon the framework by conducting a study that provides evidence from multiple organisations, from multiple innovations, or by comparing distinct adoption settings (i.e., mandatory and voluntary). Other research opportunities exist in exploring the extent of the mandatoriness in several different research contexts or innovation adoption scenarios. 


\section{References}

Ajzen, I. (1985). From intentions to actions: A theory of planned behavior. In J. Kuhl \& J. Beckmann (Eds.), Action Contol (pp. 11-39). Heidelberg, Germany: Springer.

Ajzen, I. (1991). The theory of planned behavior. Organizational Behavior and Human Decision Processes, 50(2), 179-211. doi: 10.1016/0749-5978(91)90020-T

Al-Shboul, M., Al-Saideh, M., \& Al-Labadi, N. (2017). Learners' perspectives of using ICT in higher education institutions in Jordan. Instructional Technology, 14(3), 27-86.

Asian Development Bank. (2011). Higher education across Asia: An overview of issues and strategies. Manila, Philippines: Asian Development Bank.

Asian Development Bank. (2012). Private higher education across Asia: Expanding access, searching for quality. Manila, Philippines: Asian Development Bank.

Aubrey, R., \& Cohen, P. M. (1995). Working wisdom: Timeless skills and vanguard strategies for learning organizations. San Fransisco, CA: Jossey-Bass Publishers.

Bagozzi, R. P. (2007). The legacy of the technology acceptance model and a proposal for a paradigm shift. Journal of the Association for Information Systems, 8(4), 3. doi: 10.17705/1jais.00122

Bandara, W., Furtmueller, E., Gorbacheva, E., Miskon, S., \& Beekhuyzen, J. (2015). Achieving rigor in literature reviews: Insights from qualitative data analysis and tool-support. Communications of the Association for Information Systems, 37, 154-204.

Beath, C. M. (1991). Supporting the information technology champion. MIS Quarterly, 355-372. doi: $10.2307 / 249647$

Benbasat, I., \& Barki, H. (2007). Quo vadis TAM? Journal of the Association for Information Systems, 8(4), 7. doi: 10.17705/1jais.00126

Boell, S. K., \& Cecez-Kecmanovic, D. (2015). On being 'systematic' in literature reviews in IS. Journal of Information Technology, 30(2), 161-173. doi: 10.1057/jit.2014.26

Boyne, G. A. (2002). Public and private management: What's the difference? Journal of Management Studies, 39(1), 97-122. doi: 10.1111/1467-6486.00284

Brown, S. A., Massey, A. P., Montoya-Weiss, M. M., \& Burkman, J. R. (2002). Do I really have to? User acceptance of mandated technology. European Journal of Information Systems, 11(4), 283-295. doi: 10.1057/palgrave.ejis.3000438

Burton-Jones, A., \& Gallivan, M. J. (2007). Toward a deeper understanding of system usage in organizations: A multilevel perspective. MIS Quarterly, 31(4), 657-679. doi: $10.2307 / 25148815$

Burton-Jones, A., \& Straub Jr, D. W. (2006). Reconceptualizing system usage: An approach and empirical test. Information Systems Research, 17(3), 228-246. doi: 10.1287/isre.1060.0096

Caudle, S. L., Gorr, W. L., \& Newcomer, K. E. (1991). Key information systems management issues for the public sector. MIS Quarterly, 15(2), 171-188. doi: 10.2307/249378

Chaputula, A. H. (2012). State, adoption and use of ICTs by students and academic staff at Mzuzu University, Malawi. Program Electronic Library and Information Systems, 46(4), 364382. doi: $10.1108 / 00330331211276477$ 
Chatterjee, D., Grewal, R., \& Sambamurthy, V. (2002). Shaping up for e-commerce: Institutional enablers of the organizational assimilation of web technologies. MIS Quarterly, 26(2), 65-89. doi: 10.2307/4132321

Chuttur, M. Y. (2009). Overview of the technology acceptance model: Origins, developments and future directions. Working Papers on Information Systems, 9(37), 9-37.

Cooper, R. B., \& Zmud, R. W. (1990). Information technology implementation research: A technological diffusion approach. Management Science, 36(2), 123-139. doi: 10.1287/mnsc.36.2.123

Creswell, J. W. (2013). Qualitative inquiry and research design: Choosing among five approaches (3rd ed.). Thousand Oaks, CA: Sage.

Davis, F. D. (1986). A technology acceptance model for empirically testing new end-user information systems: Theory and results (Doctoral dissertation, Massachusetts Institute of Technology). Retrieved from https://dspace.mit.edu.

Davis, F. D. (1989). Perceived usefulness, perceived ease of use and user acceptance of information technology. MIS Quarterly, 13(3), 319-340. doi: 10.2307/249008

Davis, F. D., Bagozzi, R. P., \& Warshaw, P. R. (1989). User acceptance of computer technology: A comparison of two theoretical models. Management Science, 35(8), 982-1003. doi: 10.1287/mnsc.35.8.982

DeLone, W., and McLean, E.R. (1992). Information systems success: The quest for the dependent variable. Information Systems Research, 3(1), 60-95. doi:10.1287/isre.3.1.60

Eisenhardt, K. M. (1989). Building theories from case study research. Academy of Management Review, 14(4), 532-550. doi: 10.5465/amr.1989.4308385

Fiato, K. A. (2012). Enhancing electronic medical records (EMR) implementation: Peer support interventions influencing nurses' acceptance and use (Doctoral dissertation, Capella University). Available from ProQuest Dissertations and Theses database. (UMI No. 3499912).

Fishbein, M., \& Ajzen, I. (1975). Belief, attitude, intention, and behavior: An introduction to theory and research. Reading, MA: Addison-Wesley Publishing Company.

Frambach, R. T., \& Schillewaert, N. (2002). Organizational innovation adoption: A multi-level framework of determinants and opportunities for future research. Journal of Business Research, 55(2), 163-176. doi: 10.1016/S0148-2963(00)00152-1

Gallivan, M. J. (2001a). Meaning to change: How diverse stakeholders interpret organizational communication about change initiatives. IEEE Transactions on Professional Communication, 44(4), 243-266. doi: 10.1109/47.968107

Gallivan, M. J. (2001b). Organizational adoption and assimilation of complex technological innovations: Development and application of a new framework. ACM SIGMIS Database, 32(3), 51-85. doi: 10.1145/506724.506729

Gallivan, M. J. (2004). Examining IT professionals' adaptation to technological change: The influence of gender and personal attributes. ACM SIGMIS Database, 35(3), 28-49. doi: 10.1145/1017114.1017119 
Gallivan, M. J., Spitler, V. K., \& Koufaris, M. (2005). Does information technology training really matter? A social information processing analysis of coworkers' influence on IT usage in the workplace. Journal of Management Information Systems, 22(1), 153-192. doi: 10.1080/07421222.2003.11045830

Heintze, T., \& Bretschneider, S. (2000). Information technology and restructuring in public organizations: Does adoption of information technology affect organizational structures, communications, and decision making? Journal of Public Administration Research and Theory, 10(4), 801-830. doi: 10.1093/oxfordjournals.jpart.a024292

Hsieh, S.T., \& Hsu, P.Y. (2013). Mentoring effects in the successful adaptation of information systems. Information Development, 31(2), 164-175. doi: 10.1177/0266666913511263

Huda, M. Q., \& Hussin, H. (2010). ICT implementation barriers and organizational issues in Islamic-based higher education institution: The case of Syarif Hidayatullah State Islamic University (UIN) Jakarta. Proceedings of the 3rd International Conference on Information and Communication Technology for the Moslem World (ICT4M) 2010 (pp. A18-A25). Jakarta, Indonesia: IEEE.

Jasperson, J. S., Carter, P. E., \& Zmud, R. W. (2005). A comprehensive conceptualization of post-adoptive behaviors associated with information technology enabled work systems. MIS Quarterly, 29(3), 525-557. doi: 10.2307/25148694

Klein, H. K., \& Myers, M. D. (1999). A set of principles for conducting and evaluating interpretive field studies in information systems. MIS Quarterly, 23(1), 67-93. doi: $10.2307 / 249410$

Lee, Y., Kozar, K. A., \& Larsen, K. R. (2003). The technology acceptance model: Past, present, and future. Communications of the Association for Information Systems, 12(1), 50.

Leonard-Barton, D. (1988). Implementation characteristics of organizational innovations: Limits and opportunities for management strategies. Communication Research, 15(5), 603631. doi: 10.1177/009365088015005006

Leonard-Barton, D., \& Deschamps, I. (1988). Managerial influence in the implementation of new technology. Management Science, 34(10), 1252-1265. doi: 10.1287/mnsc.34.10.1252

Meerza, A. H., \& Beauchamp, G. (2017). Factors influencing attitudes towards information and communication technology (ICT) amongst undergraduates: An empirical study conducted in Kuwait higher education institutions (KHEIs). The Turkish Online Journal of Educational Technology, 16(2), 35-42.

Miles, M. B., Huberman, A. M., \& Saldaña, J. (2014). Qualitative data analysis: A methods sourcebook. Thousand Oaks, CA: Sage.

Myers, M. D. (2013). Qualitative research in business and management. Thousand Oaks, CA: Sage.

Norris, D. F. (1999). Leading edge information technologies and their adoption: Lessons from US cities. In Information technology and computer applications in public administration: Issues and trends (pp. 137-156). IGI Global. doi: 10.4018/978-1-87828-952-0.ch008

Orlikowski, W. J., \& Baroudi, J. J. (1991). Studying information technology in organizations: Research approaches and assumptions. Information Systems Research, 2(1), 1-28. doi: 10.1287/isre.2.1.1 
Othman, A., Pislaru, C., Kenan, T., \& Impes, A. (2013). Analyzing the effectiveness of IT strategy in Libyan higher education institutes. International Journal of Digital Information and Wireless Communications, 3(3), 114-129.

Purvis, R. L., Sambamurthy, V., \& Zmud, R. W. (2001). The assimilation of knowledge platforms in organizations: An empirical investigation. Organization Science, 12(2), 117135. doi: 10.1287/orsc.12.2.117.10115

Ram, S., \& Jung, H.-S. (1991). "Forced" adoption of innovations in organizations: Consequences and implications. Journal of Product Innovation Management, 8(2), 117-126. doi: 10.1016/0737-6782(91)90005-J

Rogers, E. M. (1962). Diffusion of innovations (1st ed.). New York, NY: Free Press.

Rogers, E. M. (2003). Diffusion of innovations (5th ed.). New York, NY: Free Press.

Saldaña, J. (2015). The coding manual for qualitative researchers. Thousand Oaks, CA: Sage.

Seddon, P. (1997). A Respecification and Extension of the DeLone and McLean Model of IS Success. Information Systems Research, 8(3), 240-253. doi:10.1287/isre.8.3.240

Setiawan, I. (2012). A case study of IT implementation in public university: Its barriers and challenges. Jurnal Ilmu Komputer, 5(2), 43-52.

Shaikh, Z. A. (2009). Usage, acceptance, adoption, and diffusion of information \& communication technologies in higher education: A measurement of critical factors. Journal of Information Technology Impact, 9(2), 63-80.

Stake, R. E. (1995). The art of case study research. Thousand Oaks, CA: Sage.

Taylor, S., \& Todd, P. A. (1995). Understanding information technology usage: A test of competing models. Information Systems Research, 6(2), 144-176. doi: 10.1287/isre.6.2.144

Tilton, J. E. (1971). International diffusion of technology: The case of semiconductors (Vol. 4). Brookings Institution Press.

Tong, Y., Teo, H.-H., \& Tan, C.-H. (2008). Direct and indirect use of information systems in organizations: An empirical investigation of system usage in a public hospital. Proceedings of the 29th International Conference of Information Systems (ICIS) 2008 (pp. 138). Paris, France: AIS Electronic Library.

United Nations Educational, Scientific and Cultural Organization. (2009). ICTs for higher education. Paper presented at the World Conference on Higher Education, Paris, France.

United Nations Educational, Scientific and Cultural Organization. (2014). Higher education in Asia: Expanding out, expanding up. Montreal, QC: UNESCO Institute for Statistics.

Van De Ven, A. H., \& Rogers, E. M. (1988). Innovations and organizations: Critical perspectives. Communication Research, 15(5), 632-651. doi: 10.1177/009365088015005007

Venkatesh, V. (2000). Determinants of perceived ease of use: Integrating control, intrinsic motivation, and emotion into the technology acceptance model. Information Systems Research, 11(4), 342. doi: 10.1287/isre.11.4.342.11872

Venkatesh, V., \& Bala, H. (2008). Technology acceptance model 3 and a research agenda on interventions. Decision Sciences, 39(2), 273-315. doi: 10.1111/j.1540-5915.2008.00192.x 
Venkatesh, V., \& Davis, F. D. (2000). A theoretical extension of the technology acceptance model: Four longitudinal field studies. Management Science, 46(2), 186-204. doi: 10.1287/mnsc.46.2.186.11926

Venkatesh, V., Morris, M. G., Davis, G. B., \& Davis, F. D. (2003). User acceptance of information technology: Toward a unified view. MIS Quarterly, 27(3), 425-478. doi: 10.2307/30036540

Venkatesh, V., Thong, J. Y., \& Xu, X. (2012). Consumer acceptance and use of information technology: Extending the unified theory of acceptance and use of technology. MIS Quarterly, 36(1), 157-178.

Walsham, G. (1995). Interpretive case studies in IS research: Nature and method. European Journal of Information Systems, 4(2), 74-81. doi: 10.1057/ejis.1995.9

Walsham, G. (2006). Doing interpretive research. European Journal of Information Systems, 15(3), 320-330. doi: 10.1057/palgrave.ejis.3000589

Williamson, K., \& Johanson, G. (2013). Research methods: Information, systems and contexts. Prahran, Australia: Tilde University Press.

Wilson, K. B., Tete-Mensah, I., \& Boateng, K. A. (2014). Information and communication technology use in higher education: Perspectives from students. European Scientific Journal, 10(19), 161-171.

Yin, R. K. (2014). Case study research: Design and methods (5th ed.). Los Angeles, CA: Sage.

Zaltman, G., Duncan, R., \& Holbek, J. (1973). Innovations and organizations. New York, NY: Wiley.

Copyright: () 2018 Irawan, Foster \& Tanner. This is an open-access article distributed under the terms of the Creative Commons Attribution-NonCommercial 3.0 Australia License, which permits non-commercial use, distribution, and reproduction in any medium, provided the original author and AJIS are credited.

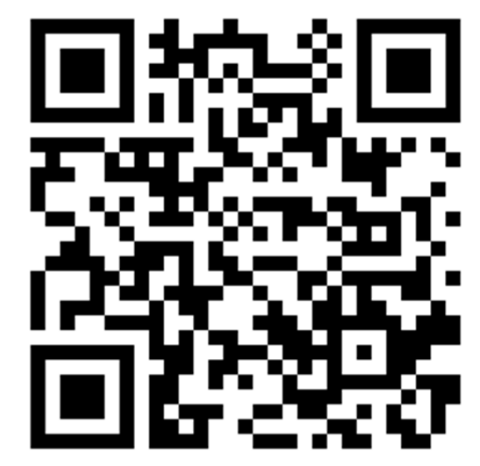

